\title{
REEXPLORATION FOR BLEEDING IS A RISK FACTOR FOR ADVERSE OUTCOMES AFTER CARDIAC OPERATIONS
}

\author{
Michael J. Moulton, MD \\ Lawrence L. Creswell, MD \\ Mary E. Mackey, BA \\ James L. Cox, MD \\ Michael Rosenbloom, MD
}

\begin{abstract}
Objective: Although previous studies have included early reexploration for bleeding as a risk factor in analyzing adverse outcomes after cardiac operations, reexploration for bleeding has not been systematically examined as a multivariate risk factor for increased morbidity and mortality after cardiac surgery. Furthermore, multivariate predictors of the need for reexploration have not been identified. Accordingly, we performed a retrospective analysis of 6100 patients requiring cardiopulmonary bypass from January 1, 1986, to December 31, 1993. Methods: Eighty-five patients who had ventricular assist devices were excluded from further analysis because of the prevalence of bleeding and the significant morbidity and mortality associated with placement of a ventricular assist device, unrelated to reexploration. In the remaining 6015 patients, potential adverse outcomes analyzed included operative mortality, mediastinitis, stroke, renal failure, adult respiratory distress syndrome, prolonged mechanical ventilation, sepsis, atrial arrhythmias, and ventricular arrhythmias. To control for the confounding effects of other risk factors, we performed a multivariate logistic regression analysis. Potential covariates considered in the logistic model included age, sex, race, history of reoperation, urgency of the operation, congestive heart failure, prior myocardial infarction, renal failure, diabetes, hypertension, chronic obstructive pulmonary disease or stroke, and the bypass and crossclamp time. Results: The overall incidence of reexploration was $4.2 \%(253 / 6015)$. Four independent risk factors-increased patient age $(p<0.001)$, preoperative renal insufficiency $(p=0.02)$, operation other than coronary bypass $(p<0.001)$, and prolonged bypass time $(p=$ 0.03 ) - were identified as predictors of the need for reexploration. The preoperative use of aspirin, heparin, or thrombolytic agents and the bleeding time were not identified as predictors. Reexploration for bleeding was identified as a strong independent risk factor for operative mortality $(p=0.005)$, renal failure $(p<0.0001)$, prolonged mechanical ventilation $(p<0.0001)$, adult respiratory distress syndrome $(p=0.03)$, sepsis $(p<0.0001)$, and atrial arrhythmias $(p=0.006)$. Conclusion: These data indicate that meticulous attention to surgical hemostasis and possibly application of recently developed modalities designed to facilitate perioperative correction of coagulopathy could improve outcomes after cardiac operations. (J Thorac Cardiovasc Surg 1996; 111:1037-46)
\end{abstract}

$\mathrm{M}$ any studies have examined the application of perioperative measures designed to reduce bleeding, ${ }^{1}$ but only a single recent study has com-

From the Department of Surgery, Division of Cardiothoracic Surgery, Washington University, St. Louis, Mo.

Read at the Twenty-first Annual Meeting of The Western Thoracic Surgical Association, Coeur d'Alene, Idaho, June 21-24, 1995.

Received for publication June 21, 1995; revisions requested Oct. 24, 1995; revisions received Dec. 28, 1995; accepted for publication Jan. 3, 1996 pared the outcome of patients who required reexploration with that of patients who did not. ${ }^{2}$ Applying stepwise multivariate logistic regression, Unsworth-White and associates ${ }^{2}$ found early reexploration for bleeding to be an independent risk

\footnotetext{
Address for reprints: Michael Rosenbloom, MD, Division of Cardiothoracic Surgery, 3108 Queeny Tower, One Barnes Hospital Plaza, St. Louis, MO 63110.

Copyright (C) 1996 by Mosby-Year Book, Inc.

$0022-5223 / 96 \$ 5.00+0 \quad \mathbf{1 2 / 6 / 7 1 5 9 7}$
} 
factor for operative mortality, prolonged intensive care unit (ICU) stay, and the need for an intraaortic balloon pump. Although prior studies have found early reexploration for bleeding to be an independent multivariate risk factor for specific adverse outcomes after cardiac operations for such conditions as atrial fibrillation ${ }^{3}$ and deep sternal wound infection, ${ }^{4}$ no study has focused on both the risk factors for and the consequences of early reexploration for bleeding.

Recent clinical trials have demonstrated the efficacy of aprotinin ${ }^{1}$ or desmopressin acetate $^{5}$ for reducing the amount of postoperative bleeding. However, these trials were not large enough to demonstrate conclusively a reduction in perioperative morbidity or mortality. In contrast, retrospective analysis of a large group of patients undergoing procedures requiring cardiopulmonary bypass (CPB) might identify the consequences of postoperative bleeding and, therefore, may indirectly provide the basis for further clinical trials. If the consequences of reexploration and excessive bleeding were minimal, then these agents would not be likely to have an important impact; conversely, if the consequences were significant, these agents may substantially reduce morbidity and mortality.

The objective of the present study was to assess the significance of early reexploration for bleeding on morbidity and mortality after cardiac operations. Additionally, we sought to identify patients at high risk for perioperative bleeding and reexploration to aid in treatment strategies designed to reduce bleeding and the attendant risks of transfusion. Specifically, using multivariate logistic regression, we examined the effects of early reexploration on operative mortality, mediastinitis, stroke, renal failure, adult respiratory distress syndrome (ARDS), prolonged mechanical ventilation, sepsis, atrial arrhythmias, and ventricular arrhythmias. Additionally, we used logistic regression to screen for preoperative and intraoperative risk factors for early reexploration for bleeding.

\section{Methods}

Between January 1, 1986, and December 31, 1993, a total of 6100 patients underwent cardiac surgical procedures necessitating CPB at Barnes Hospital, Washington University Medical Center, St. Louis. In conjunction with cardiac surgery, 85 patients underwent placement of a ventricular assist device and were excluded from further analysis because of the prevalence of bleeding and the high rate of mortality and morbidity in this patient population, unrelated to reexploration. Characteristics of the study group are listed in Table I.
Demographic data regarding each patient were obtained retrospectively from the patient's chart before hospital discharge and were entered into a computer database. Pertinent information for the current study included the patient's age, sex, race, urgency of the procedure, and preoperative medical history including a history of previous cardiac operation, myocardial infarction, congestive heart failure, New York Heart Association functional class, diabetes, chronic obstructive pulmonary disease, renal insufficiency, and peripheral vascular disease. A history of bleeding disorder was sought from all patients and the preoperative use of aspirin, heparin, or thrombolytic agents was recorded. A bleeding time was obtained for 4272 of the patients $(71 \%)$ ). Recorded operative details included the CPB time, aortic crossclamp time, the number and type of distal bypasses, and use of a ventricular assist device or an intraaortic balloon pump. Postoperative details that were recorded included the need for early reexploration for bleeding, defined as the need for resternotomy within 24 hours of the first operative procedure, amount of postoperative bleeding, and amount of blood products required. Recorded outcomes were the operative mortality defined as an in-hospital death, postoperative myocardial infarction, pulmonary embolus, renal failure, prolonged mechanical ventilation, cerebrovascular accident, atrial and ventricular arrhythmias, deep sternal wound infection, superficial sternal wound infection, and saphenous vein harvest site (leg) infection. Postoperative myocardial infarction was defined by clinical criteria and electrocardiographic changes or characteristic serum enzyme elevations (creatine kinase, lactic dehydrogenase).

The decision to return to the operating room for an adult of average weight was made by the responsible surgeon and was based on conventional guidelines ${ }^{6}$ : (1) drainage of more than $500 \mathrm{ml}$ in the first hour, total drainage of more than $800 \mathrm{ml}$ in the first 2 hours, $900 \mathrm{ml}$ in the first 3 hours, or greater than $1000 \mathrm{ml}$ in the first 4 hours or $1200 \mathrm{ml}$ in the first 5 hours; (2) sudden massive bleeding or cardiac tamponade.

Operative procedures were performed by eleven different surgeons with a variety of cannulation and cardioplegia techniques. Myocardial protection was performed most commonly with antegrade cold crystalloid cardioplegia; however, more recently there was a trend toward the use of antegrade or retrograde (cold or warm) blood cardioplegia.

The anticoagulation and reversal protocol for the first 6 years of the study (1986 to 1992) included an initial fixed dose of heparin (250 units $/ \mathrm{kg}$ ) and additional boluses of 5000 units of heparin when the activated clotting time fell below 480 seconds during the CPB run. Heparin was neutralized with a fixed dose of protamine $(0.8 \mathrm{mg}$ protamine per milligram total heparin dose). For the interval from 1992 to 1993, a new protocol was established on the basis of the results of a prospective, randomized trial. ${ }^{7}$ An initial dose of heparin was based on an automated heparin dose-response assay. Additional heparin doses were administered if the heparin concentration was less than the reference concentration or for an activated clotting time less than 480 seconds. The protamine dose was based on the initial heparin concentration. 
Table I. Preoperative patient characteristics

\begin{tabular}{|c|c|c|c|}
\hline Characteristic & Reexploration* $(n=253)$ & No reexploration $(n=5762)$ & $p$ Valuet \\
\hline Age (yr) & $63.4 \pm 13.2$ & $61.5 \pm 13.2$ & $p=0.02$ \\
\hline Male $(\operatorname{sex})(\%)$ & 61.9 & 65.7 & $p=0.19$ \\
\hline White (race) $(\%)$ & 77.1 & 78.8 & $p=0.61$ \\
\hline Procedure (\% CABG) & 54.8 & 69.2 & $p<0.001$ \\
\hline NYHA class (mean) & $1.1 \pm 1.1$ & $1.6 \pm 1.0$ & $p=0.001$ \\
\hline \multicolumn{4}{|l|}{ Range (I-IV) } \\
\hline Previous MI (mean No.) & $0.73 \pm 0.90$ & $0.74 \pm 0.88$ & $p=0.90$ \\
\hline Urgent/emergency operation & 32.1 & 23.9 & $p=0.007$ \\
\hline Previous cardiac operation & 6.7 & 13.0 & $p=0.05$ \\
\hline History of preoperative aspirin use & 43.2 & 46.6 & $p=0.30$ \\
\hline Bleeding time (min) & $6.2 \pm 3.1$ & $6.1 \pm 3.0$ & $p=0.88$ \\
\hline History of bleeding & 0.4 & 0.5 & $p=1.0$ \\
\hline Preoperative heparin use & 32.5 & 29.7 & $p=0.32$ \\
\hline Preoperative thrombolytic use & 3.2 & 4.6 & $p=0.30$ \\
\hline \multicolumn{4}{|l|}{ Preoperative history } \\
\hline Diabetes mellitus & 21.8 & 24.1 & $p=0.37$ \\
\hline Chronic renal insufficiency & 15.9 & 9.5 & $p<0.0001$ \\
\hline Preoperative dialysis & 0.7 & 0.7 & $p=0.93$ \\
\hline Hypertension & 56.1 & 55.2 & $p=0.79$ \\
\hline COPD & 13.8 & 12.2 & $p=0.39$ \\
\hline Stroke & 8.0 & 7.8 & $p=0.92$ \\
\hline LV ejection fraction $\neq$ & 0.51 & 0.53 & $p=0.17$ \\
\hline Cardiac index $\left(\mathrm{L} \cdot \mathrm{min}^{-1} \cdot \mathrm{m}^{-2}\right)$ & 2.4 & 2.4 & $p=0.30$ \\
\hline CPB time (min) & $154.4 \pm 77.3$ & $124.6 \pm 53.8$ & $p<0.0001$ \\
\hline Aortic crossclamp time (min) & $68.6 \pm 43.5$ & $58.8 \pm 36.0$ & $p<0.0001$ \\
\hline
\end{tabular}

NYHA, New York Heart Association; $M I$, myocardial infarction; COPD, chronic obstructive pulmonary disease; $L V$, left ventricular.

${ }^{*}$ Reexploration group excludes patients with ventricular assist devices.

$\dagger$ †Binary variables were compared by means of Fisher's exact test and continuous variables were compared by means of an independent Student's $t$ test. Boldface type indicates that the $p$ value is significant.

$\doteqdot$ Data were available on only a subgroup of the entire patient group.

Pharmacologic adjuncts for controlling microvascular bleeding including desmopressin acetate were administered in the setting of clinical bleeding when point-of-care hemostasis demonstrated the presence of platelet dysfunction. Approximately $10 \%$ to $15 \%$ of the patients received desmopressin acetate. Aprotinin was used rarely because of concern about hypercoagulability and its effects on graft patency. Aminocaproic acid (Amicar) was used for patients in whom the risk of bleeding was high, including those undergoing combined coronary artery bypass grafting $(\mathrm{CABG})$ and valve operations or repair of thoracic aneurysms.

Statistical analysis was performed with SYSTAT for Windows (Statistics, version 5 edition, 1992, SYSTAT, Inc., Evanston, Ill.), and the multivariate logistic regression was performed with the LOGIT module from SYSTAT (Steinberg, D and Colla, P. LOGIT: a supplementary module for SYSTAT, 1991). Descriptive data were given as mean \pm standard deviation and comparisons between continuous variables were performed with Student's $t$ test. Categoric variables were compared with a $\mathrm{X}^{2}$ test or Fisher's exact test as appropriate. Multivariate stepwise logistic regression was performed in a negative fashion by including variables in the model with a $p$ value 0.15 or less and excluding variables with a $p$ value greater than 0.20 as recommended in Hosmer and Lemeshow. $^{8}$ In all cases, a $p$ value of 0.05 or less was considered to be significant.

\section{Results}

The overall rate of reexploration was $4.2 \%$ (253/ 6015 ). The rate of reexploration for patients undergoing isolated primary or reoperative $\mathrm{CABG}$ was $3.3 \%$ (134/4092). Patients undergoing reexploration for bleeding had a longer ICU stay $(4.5 \pm 7.9$ days versus $9.7 \pm 12.7$ days; $p<0.0001)$ and a longer total hospital stay $(13.1 \pm 14.6$ days versus $20.5 \pm$ 22.4 days; $p<0.0001$ ) than patients not requiring reexploration.

Patient characteristics. The group requiring early reexploration for bleeding differed in several respects from the control group (see Table I). Specifically, the reexploration group was older $(p=$ 0.02 ), underwent a higher percentage of procedures other than CABG $(p<0.001)$, had a higher incidence of urgent or emergency operation ( $p=$ 0.007 ), and contained more patients undergoing a reoperation $(p=0.05)$. Additional differences included a higher prevalence of chronic renal insufficiency not necessitating dialysis $(p<0.0001)$ and a longer CPB and aortic crossclamp time. Notably, the two groups did not differ in the preoperative use of 
Table II. Multivariate logistic regression analysis of preoperative risk factors for early re-exploration for bleeding

\begin{tabular}{lccc}
\hline & \multicolumn{3}{c}{$95 \%$} \\
\cline { 3 - 4 } \multicolumn{1}{c}{ Variable } & $\begin{array}{c}\text { Odds } \\
\text { ratio }\end{array}$ & $\begin{array}{c}\text { Confidence } \\
\text { interval }\end{array}$ & $p$ Value \\
\hline Age & 1.01 & $1.00-1.02$ & $p<\mathbf{0 . 0 0 1}$ \\
Sex & 1.1 & $0.9-1.5$ & $p=0.30$ \\
Procedure & 1.9 & $1.5-2.5$ & $p<\mathbf{0 . 0 0 1}$ \\
NYHA class & 1.1 & $1.0-1.3$ & $p=0.09$ \\
Urgent/emergency procedure & 1.1 & $1.0-1.3$ & $p=0.14$ \\
Reoperation & 0.9 & $0.7-1.3$ & $p=0.70$ \\
Renal insufficiency & 1.5 & $1.0-2.1$ & $p=\mathbf{0 . 0 2}$ \\
History of bleeding & 0.7 & $0.1-5.4$ & $p=0.75$ \\
Bleeding time & 1.0 & $0.9-1.0$ & $p=0.36$ \\
Aspirin use & 0.9 & $0.7-1.1$ & $p=0.28$ \\
Heparin & 1.0 & $0.8-1.3$ & $p=0.84$ \\
Thrombolytic agents & 0.6 & $0.2-1.5$ & $p=0.26$ \\
Ejection fraction & 0.5 & $0.2-1.2$ & $p=0.12$ \\
CPB time & 1.003 & $1.0-1.005$ & $p=\mathbf{0 . 0 3}$ \\
Crossclamp time & 0.996 & $0.99-1.001$ & $p=0.15$ \\
\hline
\end{tabular}

NYHA, New York Heart Association. Boldface type indicates that the $p$ value is significant.

Table III. Postoperative bleeding

\begin{tabular}{lccc}
\hline $\begin{array}{c}\text { Chest tube } \\
\text { drainage }\end{array}$ & Reexploration & Noexploration & $p$ Value \\
\hline Within $12 \mathrm{hr} .(\mathrm{ml})$ & $766 \pm 891$ & $292 \pm 260$ & $p<0.0001$ \\
Within $24 \mathrm{hr} .(\mathrm{ml})$ & $2088 \pm 1292$ & $648 \pm 456$ & $p<0.0001$ \\
\hline
\end{tabular}

aspirin $(p=0.30)$, the use of thrombolytic agents $(p=0.30)$ or heparin $(p=0.32)$, the preoperative bleeding time $(p=0.88)$, or in the preoperative history of a bleeding disorder $(p=1.0)$.

Preoperative risk factors for early reexploration. The preoperative variables listed in Table I were entered into a multivariate logistic regression model to screen for risk factors leading to bleeding complications necessitating early reexploration. The results of the decreasing stepwise logistic regression analysis are presented in Table II. Only four variables-age $(p<0.001)$, preoperative renal insufficiency $(p=0.02)$, procedure other than CABG $(p<$ $0.001)$, and prolonged CPB time $(p=0.03)$ emerged as independent multivariate predictors of the need for early reexploration. Notably, the preoperative use of aspirin, heparin, or thrombolytic agents, the history of a bleeding disorder, and the bleeding time were not multivariate predictors of the need for early reexploration.

Amount of postoperative bleeding and use of blood products. Patients requiring early reexploration averaged $766 \pm 891 \mathrm{ml}$ of mediastinal chest
Table IV. Intraoperative and postoperative use of homologous blood products

\begin{tabular}{|c|c|c|c|}
\hline Blood product & Reexploration & $\begin{array}{l}\text { No } \\
\text { reexploration }\end{array}$ & $p$ Value \\
\hline \multicolumn{4}{|l|}{ Packed cells (intraop.) } \\
\hline $\begin{array}{l}\% \text { Patients not } \\
\text { requiring }\end{array}$ & 8.7 & 45.1 & \\
\hline Mean No. of units & $4.0 \pm 1.0$ & $3.3 \pm 1.0$ & $p<0.0001$ \\
\hline \multicolumn{4}{|l|}{$\begin{array}{l}\text { Fresh frozen } \\
\text { plasma (intraop.) }\end{array}$} \\
\hline $\begin{array}{l}\% \text { Patients not } \\
\text { requiring }\end{array}$ & 29.2 & 67.7 & \\
\hline Mean No. of units & $3.3 \pm 1.1$ & $2.8 \pm 1.0$ & $p<0.0001$ \\
\hline \multicolumn{4}{|l|}{ Packed cells (postop.) } \\
\hline $\begin{array}{l}\% \text { Patients not } \\
\text { requiring }\end{array}$ & 2.8 & 29.5 & \\
\hline Mean No. of units & $4.4 \pm 0.7$ & $3.4 \pm 0.9$ & $p<0.0001$ \\
\hline \multicolumn{4}{|l|}{$\begin{array}{l}\text { Fresh frozen plasma } \\
\text { (postop.) }\end{array}$} \\
\hline $\begin{array}{l}\% \text { Patients not } \\
\text { requiring }\end{array}$ & 13.4 & 69.5 & \\
\hline Mean No. of units & $3.5 \pm 1.0$ & $2.7 \pm 1.0$ & $p<0.0001$ \\
\hline
\end{tabular}

tube drainage in the first 12 hours after the operation compared with $292 \pm 260 \mathrm{ml}$ in the control group (Table III). These patients averaged $2088 \pm$ $1292 \mathrm{ml}$ of mediastinal chest tube drainage in the first 24 hours after the operation compared with $648 \pm 456 \mathrm{ml}$ for the control group. The control group was more than five times more likely to avoid intraoperative homologous transfusion of packed red blood cells ( $45.1 \%$ to $8.7 \%$ ) than the reexploration group and more than ten times more likely to avoid postoperative homologous blood transfusion (29.5\% to $2.8 \%$ ) (Table IV). The patients who did require intraoperative transfusion in both groups averaged $4.0 \pm 1.0$ units of packed red blood cells for the reexploration group versus $3.3 \pm 1.0$ units for the control group $(p<0.0001)$. The postoperative transfusion requirement for those patients needing transfusion was $4.4 \pm 0.7$ units for the reexploration group and $3.4 \pm 0.9$ units for the control group $(p<$ 0.0001 ). Similarly, both intraoperative and postoperative transfusion of fresh frozen plasma were more common in the reexploration group than in the control group (intraoperative: $67.7 \%$ to $29.2 \%$; $p<0.0001$; postoperative: $69.5 \%$ to $13.4 \% ; p<$ 0.0001 ) (Table IV).

Reexploration as a risk factor for adverse outcomes. The preoperative variables listed in Table I were included with reexploration for bleeding in a multivariate stepwise logistic model for each adverse outcome. Reexploration was included as a forced factor and patients with ventricular assist devices 
Table V. Reexploration as a multivariate risk factor for adverse outcomes

\begin{tabular}{|c|c|c|c|c|c|c|c|c|}
\hline \multirow[b]{3}{*}{ Outcome $(n=6015)$} & \multirow[b]{3}{*}{ No. } & \multirow[b]{3}{*}{$\%$} & \multicolumn{4}{|c|}{ Relationship of outcome to reexploration } & \multirow{3}{*}{$\begin{array}{c}\text { Multivariate } \\
p \text { value }\end{array}$} & \multirow{3}{*}{$\begin{array}{l}\text { Odd } \\
\text { ratio }\end{array}$} \\
\hline & & & \multicolumn{2}{|c|}{$\begin{array}{c}\text { Reexploration } \\
(n=253)\end{array}$} & \multicolumn{2}{|c|}{$\begin{array}{l}\text { No reexploration } \\
\quad(n=5762)\end{array}$} & & \\
\hline & & & No. & $\%$ & No. & $\%$ & & \\
\hline Operative mortality & 270 & 4.5 & 27 & 10.7 & 243 & 4.2 & 0.005 & 2.0 \\
\hline Mediastinitis & 58 & 1.0 & 6 & 2.4 & 52 & 0.9 & 0.256 & 1.8 \\
\hline Stroke & 120 & 2.0 & 9 & 3.6 & 111 & 1.9 & 0.288 & 1.5 \\
\hline Renal failure & 259 & 4.3 & 40 & 15.8 & 219 & 3.8 & $<0.0001$ & 3.9 \\
\hline ARDS & 109 & 1.8 & 11 & 4.3 & 98 & 1.7 & 0.030 & 2.1 \\
\hline $\begin{array}{l}\text { Prolonged mechanical } \\
\text { ventilation }\end{array}$ & 555 & 9.2 & 62 & 24.5 & 493 & 8.6 & $<0.0001$ & 3.1 \\
\hline Sepsis & 244 & 4.1 & 32 & 12.6 & 212 & 3.7 & $<0.0001$ & 3.0 \\
\hline Atrial arrhythmias & 2011 & 33.4 & 111 & 43.9 & 1900 & 33.0 & 0.006 & 1.5 \\
\hline Ventricular arrhythmias & 324 & 5.4 & 21 & 8.3 & 303 & 5.3 & 0.153 & 1.4 \\
\hline
\end{tabular}

ARDS, Adult respiratory distress syndrome

* A multivariate decreasing stepwise logistic regression model was developed with reexploration for bleeding as a forced factor. Patients with ventricular assist devices $(n=85)$ were excluded from the analysis. Boldface type indicates that the $p$ value is significant.

Table VI. Relationship between the amount of bleeding and outcomes stratified by reexploration

\begin{tabular}{|c|c|c|c|c|c|c|c|c|c|c|c|c|}
\hline \multirow{2}{*}{$\begin{array}{l}\text { Amount of } \\
\text { chest tube } \\
\text { drainage in } \\
24 \mathrm{hr}(\mathrm{ml})\end{array}$} & \multicolumn{2}{|c|}{$\begin{array}{c}\text { Operative death } \\
(\%)\end{array}$} & \multicolumn{2}{|c|}{ Renal failure (\%) } & \multicolumn{2}{|c|}{ Sepsis (\%) } & \multicolumn{2}{|c|}{$\begin{array}{c}\text { Prolonged } \\
\text { mechanical } \\
\text { ventilation }(\%)\end{array}$} & \multicolumn{2}{|c|}{$\operatorname{ARDS}(\%)$} & \multicolumn{2}{|c|}{$\begin{array}{c}\text { Atrial anhythmias } \\
(\%)\end{array}$} \\
\hline & $\begin{array}{c}\text { No } \\
\text { Reexpl. }\end{array}$ & Reexpl. & $\begin{array}{c}\text { No } \\
\text { Reexpl. }\end{array}$ & Reexpl. & $\begin{array}{c}\text { No } \\
\text { Reexpl. }\end{array}$ & Reexpl. & $\begin{array}{l}\text { No } \\
\text { Reexpl. }\end{array}$ & Reexpl. & $\begin{array}{c}\text { No } \\
\text { Reexpl. }\end{array}$ & Reexpl. & $\begin{array}{c}\text { No } \\
\text { Reexpl. }\end{array}$ & Reexpl. \\
\hline $\begin{array}{l}0-500 \\
\quad(n=2467)\end{array}$ & 3.0 & 12.5 & 3.8 & 12.5 & 3.6 & $18.8^{*}$ & 8.4 & $25.0^{*}$ & 1.3 & $6.3^{*}$ & 33.1 & 37.5 \\
\hline $\begin{array}{l}501-1000 \\
\quad(n=2449)\end{array}$ & 2.8 & $16.0^{*}$ & 2.7 & $24.0^{*}$ & 2.3 & 8.0 & 6.8 & $20.0^{*}$ & 1.4 & $8.0^{*}$ & 33.6 & 48.0 \\
\hline $\begin{array}{l}1001-1500 \\
\quad(n=607)\end{array}$ & 4.5 & 10.4 & 3.9 & $6.3^{*}$ & 3.9 & $6.3^{*}$ & 10.2 & $27.1^{*}$ & 2.2 & 6.3 & 35.1 & 37.9 \\
\hline $\begin{array}{l}1501-2000 \\
\quad(n=188)\end{array}$ & 4.3 & 8.3 & 9.3 & 10.4 & 12.1 & 8.3 & 23.6 & 14.6 & 6.4 & 2.1 & 41.4 & 47.9 \\
\hline $\begin{array}{l}2001-2500 \\
\quad(n=77)\end{array}$ & 12.1 & 2.3 & 9.1 & 9.1 & 9.1 & 11.4 & 30.3 & 29.6 & 6.1 & 6.8 & 51.5 & 50.0 \\
\hline $\begin{aligned}> & 2500 \\
& (n=76)\end{aligned}$ & 10.0 & 12.5 & 10.0 & 12.5 & 20.0 & 16.1 & 20.0 & 19.6 & 15.0 & 0.06 & 35.0 & 33.9 \\
\hline
\end{tabular}

Reexpl., Reexploration for bleeding; $A R D S$, adult respiratory distress syndrome.

* $p<0.05$ by Fisher's exact test.

were excluded from the analysis. Reexploration was determined to be an independent multivariate predictor of operative death (odds ratio: $2.0 ; 95 \%$ confidence interval: 1.2 to $3.1 ; p=0.005)$, postoperative renal failure $(3.9 ; 2.6$ to $5.9 ; p<0.0001)$, $\operatorname{ARDS}(2.1 ; 1.1$ to $4.2 ; p=0.03)$, prolonged mechanical ventilation $(3.1 ; 2.2$ to $3.1 ; p<0.0001)$, sepsis $(3.0 ; 1.9$ to $4.5 ; p<0.0001)$, and atrial arrhythmias $(1.5 ; 1.1$ to $1.9 ; p=0.006$ ) (Table V).

Is there a detectable difference in outcome for patients with similar amounts of bleeding, some of whom undergo reexploration and others of whom do not? Outcomes in which reexploration was significant were stratified by the amount of bleeding (chest tube drainage in 24 hours [milliliters]) and reexploration (Table VI). In general, as the amount of bleeding increased, the decision to reexplore did not affect outcome.

Reexploration as a risk factor in a low-risk subgroup. All patients who were less than 70 years of age, in New York Heart Association class I, and who were undergoing elective $\mathrm{CABG}$ were classified as a low-risk subgroup $(n=2244)$. A multivariate stepwise logistic regression analysis was performed on this subset to examine reexploration as a risk factor for adverse outcomes (Table VII). In this low-risk subgroup, reexploration remained a strong multivariate risk factor for operative death $(p=0.03)$, renal 
Table VII. Reexploration as a multivariate risk factor for adverse outcomes in a "low-risk" subgroup

\begin{tabular}{|c|c|c|c|c|c|c|c|c|}
\hline \multirow{3}{*}{$\begin{array}{c}\text { Outcome } \\
(n=2244)\end{array}$} & \multirow[b]{3}{*}{ No. } & \multirow[b]{3}{*}{$\%$} & \multicolumn{4}{|c|}{ Relationship of outcome to reexploration } & \multirow{3}{*}{$\begin{array}{c}\text { Multivariate } \\
\text { p value* }\end{array}$} & \multirow{3}{*}{$\begin{array}{l}\text { Odds } \\
\text { ratio }\end{array}$} \\
\hline & & & \multicolumn{2}{|c|}{$\begin{array}{l}\text { Reexploration } \\
\quad(n=62)\end{array}$} & \multicolumn{2}{|c|}{$\begin{array}{l}\text { No reexploration } \\
\quad(n=2182)\end{array}$} & & \\
\hline & & & No. & $\%$ & No. & $\%$ & & \\
\hline Operative mortality & 30 & 1.3 & 3 & 4.8 & 27 & 1.2 & 0.03 & 4.4 \\
\hline Renal failure & 21 & 0.9 & 5 & 8.1 & 16 & 0.7 & $<0.0001$ & 17.5 \\
\hline ARDS & 28 & 1.3 & 3 & 4.8 & 25 & 1.1 & 0.02 & 4.6 \\
\hline Atrial arrhythmias & 562 & 25.0 & 23 & 37.1 & 539 & 24.7 & 0.04 & 1.8 \\
\hline
\end{tabular}

ARDS, Adult respitatory distress syndrome.

*A multivariate decreasing stepwise logistic regression model was developed for all patients who were less than 70 years of age, in New York Heart Association class $\mathrm{I}$, undergoing elective CABG. Reexploration for bleeding was included as a forced factor. Patients receiving ventricular assist devices ( $n=$ 85) were excluded from the analysis.

failure $(p<0.0001)$, ARDS $(p=0.02)$, and atrial arrhythmias $(p=0.04)$.

\section{Discussion}

The decision to reexplore for postoperative bleeding is frequently a reflexive one when bleeding is excessive in the face of normal coagulation parameters, indicating a surgical cause for bleeding. However, the decision may be more complicated in the setting of elevated coagulation parameters and moderately increased postoperative bleeding. Accordingly, information about risk factors that may lead to reexploration and the consequences of early reexploration for postoperative hemorrhage may be useful to the cardiac surgeon. If the consequences of reexploration and postoperative hemorrhage are significant, then attention to surgical hemostasis and measures designed to reduce bleeding would be important. Furthermore, this information may be useful in deciding which patients should undergo reexploration. Thus the purpose of this study was to identify preoperative risk factors that predispose to reexploration for bleeding and to examine the effects of reexploration on postoperative outcomes.

The overall rate of reexploration in this study was $4.2 \%$ and is similar to previously reported rates of $3 \%$ to $5 \%{ }^{4,9}$ Multivariate logistic regression identified four preoperative and intraoperative variables that were predictive of the need for reexploration: age $(p<0.001)$, renal insufficiency $(p=0.02)$, procedure other than CABG $(p<$ $0.001)$, and CPB time $(p=0.03)$. Advanced age is frequently identified as a risk factor for adverse outcomes after cardiac surgery and may predispose to surgical causes of postoperative bleeding by alterations in the tissues, making them more friable. Alterations in the tissues may be coupled with increased calcification of the aorta and other blood vessels, complicating surgical attempts at cannulation and, later, hemostasis. Although prolonged CPB time and increased age were identified as risk factors for reexploration for bleeding, their multivariate odds ratios were low (1.01 and 1.003 , respectively).

Renal insufficiency leads to abnormalities in platelet function ${ }^{10}$ that appear to act synergistically with CPB to increase postoperative bleeding. CPB has widely known detrimental effects on platelet function, so that prolonged CPB time would be expected to lead to an increased rate of postoperative bleeding and reexploration. Patients older than 70 years of age with chronic renal insufficiency and $\mathrm{CPB}$ times longer than 120 minutes undergoing procedures other than $\mathrm{CABG}$ had a reexploration rate of $9.9 \%(20 / 202)$, or three times the rate of patients without these risk factors $(2.7 \%$; $67 / 2475$; $p<0.001$ ). Woodman and Harker ${ }^{11}$ have suggested that patients at high risk may benefit from the administration of hemostatic agents in the perioperative period. Thus older patients with chronic renal insufficiency undergoing procedures other than $C A B G$ who may be expected to have a long CPB time may benefit from the administration of aprotinin or desmopressin acetate. Both of these adjuncts have been proven to reduce postoperative bleeding in selected patients in randomized controlled trials. ${ }^{3,12}$ Nevertheless, their use is not widespread in the United States because of real and perceived problems with intravascular coagulation, ${ }^{13}$ clotting of bypass grafts, ${ }^{14}$ and renal failure. ${ }^{15}$ Given the high rate of reexploration in this subgroup of patients, however, and the adverse outcomes with reexploration for bleeding, these patients may benefit from modalities designed to improve perioperative hemostasis. Furthermore, because of their high risk of postoperative bleeding, this subgroup may 
Volume 111, Number 5

represent an ideal cohort on which to base further studies of "antibleeding therapy."

Our study did not identify preoperative aspirin, heparin, or thrombolytic use, a prolonged bleeding time, or a history of bleeding disorder as multivariate risk factors. A few small prospective studies have identified an increased bleeding time or aspirin use $^{16}$ as a risk factor for increased postoperative bleeding. In our study, aspirin also increased the amount of postoperative bleeding (706 $\pm 446 \mathrm{ml}$ vs $670 \pm 427 \mathrm{ml} ; p=0.009$ ); however, there was no significant difference in the rate of reexploration $(p=0.28)$. In fact, the odds ratios for all of the aforementioned variables were less than or equal to 1.0 and the $p$ values were not close to significance (see Table IV). It is possible that because of the perceived increased risk for patients with these risk factors, surgeons treating these patients took extra precautions to avoid bleeding complications. Nevertheless, the fact that these risk factors were of such low significance in a multivariate analysis when compared with age, renal failure, procedures other than $\mathrm{CABG}$, and $\mathrm{CPB}$ time indicates that they are not significant risk factors for early reexploration and adverse outcomes.

Almost $30 \%$ of patients who did not undergo reexploration for bleeding avoided intraoperative or postoperative homologous blood transfusion. In contrast, only $3 \%$ of patients who did undergo reexploration avoided homologous transfusion. Although blood supplies are now screened carefully for human immunodeficiency virus and hepatitis B, other viral agents are still undetectable and are highly transmissible. Consequently, avoidance of transfusion by reducing the amount of postoperative bleeding and the rate of reexploration is highly desirable and cost-effective.

Although reexploration has been identified by other investigators as a risk factor for certain adverse outcomes such as increased risk of atrial arrhythmias ${ }^{3}$ or deep sternal wound infection, ${ }^{4}$ only a single recent study has systematically investigated reexploration as a multivariate risk factor. Unsworth-White and associates ${ }^{2}$ studied 2221 patients retrospectively and identified reexploration for bleeding as a risk factor for operative mortality, increased rate of intraaortic balloon pump use, and prolonged ICU stay. Our results also identified reexploration as a risk factor for operative death, renal failure, ARDS, prolonged mechanical ventilation, sepsis, and atrial arrhythmias. We demonstrated an increased ICU and total hospital stay for patients undergoing reexploration for bleeding. With cardiac surgery coming under increasing financial scrutiny, the addition of measures designed to improve hemostasis and attention to the patient group identified in this study as being at high risk for bleeding may reduce costs as well as improve outcome.

An important question that may bear on the decision to reexplore the operative field is whether the identified increase in morbidity and mortality in the reexploration group is due only to the large amount of bleeding or if outcomes vary with the decision to reexplore for any given amount of postoperative bleeding. Stated another way, is there a detectable difference in outcome for patients with the same amount of bleeding, some of whom undergo reexploration and others of whom do not? The results in Table VI demonstrate an increase in morbidity and mortality for the patients with a small amount of bleeding (up to $1000 \mathrm{ml}$ ) who undergo reexploration. However, these results likely reflect the fact that patients with a small amount of bleeding who undergo reexploration have had a significant bleeding-associated complication such as pericardial tamponade that would independently affect their outcomes. For patients with greater amounts of bleeding, the decision to reexplore yielded no significant difference in outcomes, although as the amount of bleeding increased, patients who underwent reexploration tended to fare better. These results imply that in a patient with increased postoperative bleeding, the decision to reexplore can be made with the knowledge that the outcome will not be worsened by the decision and may be improved. Once the decision to reexplore is entertained, the increased morbidity and mortality has already ensued.

Although reexploration for bleeding affects outcome for the entire population, its effects on morbidity and mortality are perhaps most pronounced in the "low-risk" subgroup: patients less that 70 years of age, in New York Heart Association class I, and undergoing elective CABG. For this subgroup, the odds ratio for operative death is 4.4 times greater than for the group of patients who did not undergo reexploration $(4.8 \%$ vs $1.2 \% ; p=0.03$ ), their rate of renal failure was 17.5 times greater ( $8.1 \%$ vs $0.7 \% ; p<0.0001$ ), their rate of ARDS was 4.6 times greater $(4.8 \%$ vs $1.1 \% ; p=0.02)$, and their rate of atrial arrhythmias was 1.8 times greater $(37.1 \%$ vs $24.7 \% ; p=0.04)$. These results underscore the significance of reexploration as a risk factor and provide the basis for recommending 
attainment of careful surgical hemostasis in all patients. Additionally, although the rate of reexploration is low in this and other studies, careful preoperative analysis of risk for reexploration may lower this rate further and improve outcome.

In conclusion, we have demonstrated that four risk factors-age, renal insufficiency, procedure other than $\mathrm{CABG}$, and prolonged CPB timeincrease the risk of postoperative bleeding and reexploration. Reexploration is a significant multivariate predictor of increased morbidity and mortality in all patients, but specifically in a selected low-risk subgroup of patients. The amount of bleeding itself is probably the significant risk factor, and the decision to reexplore should be based on conventional guidelines, because reexploration does not likely affect the outcome after the fact.

We gratefully acknowledge the assistance of Tina $\mathrm{L}$. Burmeister and Patricia A. Locke-Buckley for data entry and retrieval.

\section{REFERENCES}

1. Lemmer JH Jr, Stanford W, Bonney SL, et al. Aprotinin for coronary bypass surgery: efficacy, safety, and influence on early saphenous vein graft patency-a multicenter, randomized, double-blind, placebo-controlled study. J Thorac Cardiovasc Surg 1994;107:543-53.

2. Unsworth-White MJ, Herriot A, Valencia O, et al. Resternotomy for bleeding after cardiac operation: a marker for increased morbidity and mortality. Ann Thorac Surg 1995; 59:664-7.

3. Creswell LL, Schuessler RB, Rosenbloom M, Cox JL. Hazards of postoperative atrial arrhythmias. Ann Thorac Surg 1993;56:539-49.

4. Ottino G, DePaulis R, Pansini S, et al. Major sternal wound infection after open-heart surgery: a multivariate analysis of risk factors in 2,579 consecutive operative procedures. Ann Thorac Surg 1987;44:173-9.

5. Salzman EW, Weinstein MJ, Reilly D, Ware JA. Adventures in hemostasis: desmopressin in cardiac surgery. Arch Surg 1993;128:212-7.

6. Kirklin JW, Barratt-Boyes BG. Cardiac surgery. New York: Wiley, 2nd ed. 1993:222-4.

7. Despotis GJ, Joist JH, Hogue CW, et al. The impact of heparin concentration and activated clotting time monitoring on blood conservation. J Thorac Cardiovasc Surg 1995;110: 46-54.

8. Hosmer DW, Lemeshow S. Applied logistic regression. New York: John Wiley, 1989.

9. Johnson JA, Gundersen AE, Stickney ID, Cogbill TH. Selective approach to sternal closure after exploration for hemorrhage following coronary artery bypass. Ann Thorac Surg 1990;49:771-4.

10. Mannucci PM, Remuzzi G, Pusineri F, et al. Deamino-8-Darginine vasopressin shortens the bleeding time in uremia. $\mathrm{N}$ Engl J Med 1983;308:8-12.
11. Woodman RC, Harker LA. Bleeding complications associated with cardiopulmonary bypass. Blood 1990;76:1680-97.

12. Salzman EW, Weinstein MJ, Weintraub RM, et al. Treatment with desmopressin acetate to reduce blood loss after cardiac surgery. N Engl J Med 1986;314:1402-6.

13. Sundt TM III, Kouchoukos NT, Saffitz JE, et al. Renal dysfunction and intravascular coagulation with aprotinin and hypothermic circulatory arrest. Ann Thorac Surg 1993;55: 1418-24.

14. Laub GW, Riebman JB, Chen C, et al. The impact of aprotinin on coronary artery graft patency. Chest 1994;106: 1370-5.

15. Lemmer JH Jr, Stanford W, Bonney SL, et al. Aprotinin for coronary artery bypass grafting: effect on postoperative renal function. Ann Thorac Surg 1995;59:132-6.

16. Ferraris VA, Ferraris SP, Lough FC, Berry WR. Preoperative aspirin ingestion increases operative blood loss after coronary artery bypass grafting. Ann Thorac Surg 1988;45:71-4.

\section{Discussion}

Dr. Frederick L. Grover (Denver, Colo.). The purpose of this study, as mentioned, was to identify the preoperative risk factors that predispose to reexploration for bleeding and to examine the effect of reexploration for bleeding on postoperative outcomes. The authors hoped that by identifying those at highest risk for bleeding, interventions could be undertaken to decrease the likelihood of this event. They reviewed 6000 patients and "forced in" reexploration for bleeding (ordinarily an outcome variable) into their multivariate analysis, with preoperative and operative variables. We have also used this technique in both the Society of Thoracic Surgeons (STS) and the Veterans Administration (VA) databases. I believe it is permissible and leads to further information.

For the purpose of this discussion I reviewed data from the VA and the STS databases to see if these large databases could support your group's findings. From 1991 to March of 1995 , approximately 25,000 patients were entered into the VA database, with a $4.8 \%$ incidence of reexploration for bleeding. For those who underwent reexploration for bleeding, the risk of death was four times that of the average patient, even greater than the twofold increase in your study. There was also an increased incidence of mediastinitis, stroke, renal failure, and prolonged mechanical ventilation. In this particular group of patients, the preoperative risk factors predictive for reoperation for bleeding were similar to yours: renal failure, prior heart surgery, emergency and urgent surgery, congestive heart failure, angina severity, age, and cardiac procedures other than $\mathrm{CABG}$.

The CABG-only data from the STS database for 1994 were reviewed, and in this group there were 65,653 patients with a $2.3 \%$ incidence of reexploration for bleeding. Those reoperated on for bleeding had an increased risk of operative mortality of 4.2 times that of those who did not have excessive bleeding; they also had an increased chance for prolonged ventilation, renal failure, septicemia, ARDS, stroke, deep sternal infection, and atrial fibrillation. Risk factors predictive for reoperation for bleeding were dialysis, steroids, cardiogenic shock, reoperation, emergency percutaneous transluminal coronary angioplasty within less than 6 hours, and several 
other variables including aspirin, although the latter was not a major predictor, with an odds ratio of only 1.097 .

The data from these two large databases therefore support your findings of a significant increase in operative mortality and morbidity associated with reoperation for bleeding. They also identify many of the same factors that are predictive of patients likely to have this unfortunate event.

I have a couple of questions. First, what are your criteria for reoperating on a patient for bleeding, and have you compared the outcomes of patients who are reoperated on relatively early versus later or who are in hemodynamically stable versus unstable condition?

Dr. Moulton. There were eleven different surgeons who performed the operations in this study. These surgeons have slightly different criteria for returning to the operation room for bleeding, although all of these surgeons followed conventional published guidelines in spirit. We analyzed our data in an attempt to determine if patients who were taken back early did better than those taken back late. We divided the patients into groups on the basis of the amount of bleeding and looked at outcomes for patients who were returned to the operating room for bleeding and those who were not. We found that patients who had a small amount of bleeding and underwent reexploration actually did worse than those with a greater amount of bleeding. The reason is probably that patients with small amounts of bleeding had serious complications, such as hemodynamic instability or pericardial tamponade.

Among the patients with greater amounts of bleeding, from 1500 to $2500 \mathrm{ml}$ in the first 24 hours, those who underwent reexploration tended to do better than those who did not undergo reexploration. This observation possibly indicates that earlier reexploration would improve outcome.

Dr. Grover. Now that you have identified a potentially high-risk group for this complication, are you intervening with aprotinin or other agents before the operation and have you had a chance to see if there has been any reduction in postoperative bleeding?

Dr. Moulton. Aprotinin is being used only as an investigational agent in our institution. Most of our surgeons still have reservations about its effects on graft patency and about the possibility that it contributes to the development of renal failure.

As mentioned in the manuscript, we do believe that patients who were identified as being at high risk for bleeding-older patients with renal insufficiency undergoing procedures other than $\mathrm{CABG}$ and who are expected to have long CPB times-make up an excellent group on which to further investigate the efficacy of aprotinin.

Over the past few years, one of our anesthesiologists has taken an interest in bleeding complications. Thus we have monitored heparin levels and measured prothrombin times and partial thromboplastin times on site. Since the institution of these measures, our incidence of bleeding complications has decreased.

Dr. D. Craig Miller (Stanford, Calif.). Do you routinely use agents like aminocaproic acid (Amicar)?

Dr. Moulton. We use agents like aminocaproic acid (Amicar) selectively. With the use of on-site heparin monitoring, we have reduced our need for other adjunctive agents to control bleeding. In most circumstances, we can determine the cause of the bleeding. In circumstances in which excessive fibrinolysis is implicated, we would use aminocaproic acid.

Dr. Winfield J. Wells. (Los Angeles, Calif.). Do your patients have a coagulation-related workup including such tests as prothrombin time, partial thromboplastin time, and bleeding time? If they do, could you draw any correlation between those tests and the incidence of bleeding?

Dr. Moulton. We do obtain a prothrombin time, a partial thromboplastin time, a platelet count, and a bleeding time on all patients. These laboratory values have been a part of routine preoperative orders for some time. The bleeding time did not correlate with the amount of bleeding.

Dr. Wells. On the basis of those findings, would you be willing to recommend that these tests be dropped from the preoperative workup in this age of increasing pressure from managed care to reduce costs?

Dr. Moulton. I believe our data would support eliminating these tests. The only possible exception might be in patients with a history that suggests a tendency toward bleeding complications, such as patients with liver disease.

Dr. John McDermott (Redding, Calif.). I understand that you are using the event of mediastinal reexploration as a marker for significant postoperative bleeding. Would it not be more accurate to express the concept that it is the bleeding itself, and the hemodynamic consequences thereof, rather than the active reexploration, that has the effect on morbidity which your investigation defines. That is to say, would it not be more accurate to change the title and the viewpoint of the article to express the clinical fact that it is the hemodynamic effects of blood loss itself, the hemodynamic effects of even subtle or moderate mediastinal accumulation on cardiac output and perfusion, especially in those fragile or elderly patients with marginal or vulnerable cerebral or mesenteric perfusion, and the effects of blood product transfusion on the lungs and kidney which cumulatively produce the morbidity that you have observed?

It would intuitively seem that mediastinal reexploration is an ameliorating event in the bleeding patient. With that thought in mind, have you defined a difference between those patients having early reexploration as compared with those patients who might have undergone exploration later or after more substantial hemodynamic consequences or more extensive blood product transfusion?

A second question is whether you were able to define a group of patients who had not undergone reexploration but in retrospect had had substantial chest tube output. Does the outcome of those with substantial postoperative bleeding or substantial blood product transfusion differ from the outcome of the reexploration group or of the subpopulation that had early reexploration?

Dr. Moulton. With respect to your first question, we had that same question too. What is the true variable that is causing the adverse outcome? We reran the analysis with "amount of bleeding" as the forced independent factor and essentially found the same results-not exactly the 
same $p$ values, but the same adverse outcomes were affected. Thus it appeared that amount of bleeding and the requirement of reexploration for bleeding were highly correlated and gave us similar results.

We also evaluated the patients who did not undergo reexploration, and the trend for the amount of bleeding to influence the outcome was less strong. As you suggest, hemodynamic instability and the requirement for multiple red cell transfusions are probably the factors that lead to renal failure, sepsis, ARDS, and ultimately increased operative mortality.
Dr. McDermott. Your study spanned the years between 1986 and 1993, that is, 7 years and more than 6000 patients. During that time did you change your heparin or heparin/protamine protocol? If so, did you notice any change in the severity or extent of postoperative bleeding after changing to a more contemporary heparin/protamine protocol?

Dr. Moulton. Yes, we did. On the basis of the intraoperative assessment of heparin levels in about 1991 or 1992, we did change our protocol. The rates of reexploration for bleeding subsequently declined over the study interval. 